\title{
Hot machining of Ti-6Al-4V: FE analysis and experimental validation
}

\author{
ASIT KUMAR PARIDA ${ }^{1, *}$ and KALIPADA MAITY ${ }^{2}$ \\ ${ }^{1}$ Department of Mechanical Engineering, Indian Institute of Technology Delhi, Delhi, India \\ ${ }^{2}$ Department of Mechanical Engineering, National Institute of Technology Rourkela, Rourkela, India \\ e-mail: asitzone4@gmail.com
}

MS received 24 April 2018; revised 2 October 2018; accepted 22 March 2019; published online 13 May 2019

\begin{abstract}
Machining process is a nonlinear process where high stress, temperature and strain are generated in the primary and secondary shear zone. It is difficult to determine these parameters experimentally and also consumes time. In this study, finite-element method (FEM) is applied to hot machining of Ti-6Al-4V alloy using DEFORM software. The simulations are used to investigate the effect of heating temperature on cutting force, cutting temperature, stress, strain and chip morphology for various machining conditions. The predicted results are compared to results obtained in room temperature and hot machining conditions. From this analysis, it is observed that hot machining reduces the cutting force, and changes the chip morphology. To validate the simulation results, an experimental trial is performed and positive coherence is achieved.
\end{abstract}

Keywords. FEM; Ti-6Al-4V; hot machining; DEFORM; cutting force; chip thickness.

\section{Introduction}

Titanium-based alloys are widely used in aerospace, nuclear, biomedical equipment and automobile sectors due to their high strength, high resistance and excellent corrosion resistance [1]. While machining these materials by conventional way, tool wear occurs rapidly due to high temperature and pressure on the cutting edge [2]. Hot machining can be used to overcome these problems, where heating is performed on the workpiece. Several researchers study the hot machining titanium alloy using different heat sources, for instance, flame [1], laser [3], induction and plasma heating [4]. Along with heating sources, tool variables such as nose radius, rake angle, tool materials and cutting edge geometry affect machinability [5].

Akasawa et al [6] use electric heating for hot machining of hard steel with cooled cutting tool. The application of hot machining is explained in two major fields. The studies on the oxidation test of tool material and the effect of tool cooling are carried out in hot machining test of various tool materials. Plasma-assisted machining is studied by different researchers, where plasma is used as a heating source to enhance machinability [7]. The effect of gas flame on tool life in machining of high manganese steel is investigated by $[8,9]$, reporting that heating significantly enhances the tool life. The effects of induction heat machining $[4,10]$ and electric hot machining [11] on tool life are studied by different researchers. Muhammad et al [12] study hot drilling using finite-element method (FEM) and nonlinear

*For correspondence temperature-dependent material behaviour. Reduction in torque and thrust force is observed at an elevated temperature compared with conventional drilling. Numerical modelling and experimental investigation of titanium alloy using hot ultrasonic machining are studied by Muhammad et al [13]. Xiang et al [14] present laser machining using 3D analysis, predicting the groove shape and temperature distribution. Temperature distribution and groove shapes are used in an iterative scheme for geometric nonlinearity. Other researchers study FEM in hot machining of hardened materials [15-18].

More experimental works are done in the field of hot machining nickel base alloys. Though some simulations using flame heat hot machining of titanium base alloys are studied, few works are reported on flame-assisted machining of titanium alloy. Moreover, no literature has discussed the effect of heating on stress, strain and temperature systematically. FEM of hot machining of Ti-6Al- $-4 \mathrm{~V}$ is simulated and experiments are conducted to validate the models in the present study.

\section{Experimentation}

A hollow tube of Ti-6Al-4V with an outer diameter $50 \mathrm{~mm}$ and thickness of $2 \mathrm{~mm}$ is taken as workpiece material. A triangular shape cutting tool (TNMA 120404) fitted with an MTGNR 2525M12 tool holder is used and a schematic diagram of machining set-up and the dimensions of the cutting tool $(I C=9.52 \mathrm{~mm}, B=12 \mathrm{~mm}, T=4 \mathrm{~mm}$, $R=0.4 \mathrm{~mm}, H=3.5 \mathrm{~mm}$ ) are shown in figure 1 . In each 


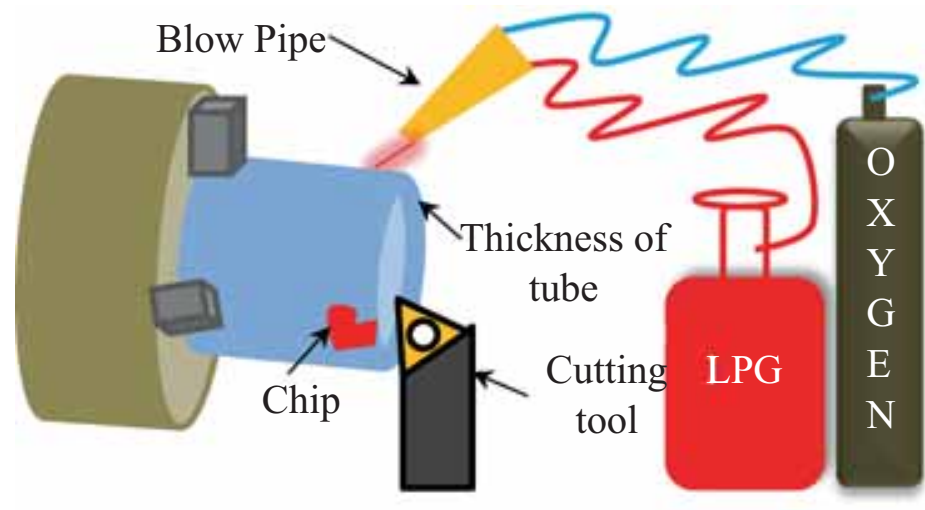

(a)

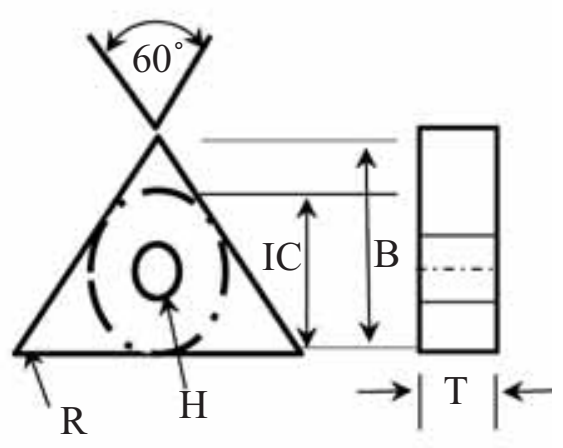

(b)

Figure 1. (a) Schematic diagram for hot machining. (b) Tool dimension.

cutting operation, a fresh cutting tool is used to avoid tool wear on the cutting tool in each experiment. The machining is carried out in the cutting speeds range of $40-100 \mathrm{~m} / \mathrm{min}$, and feed rate range of $0.1-0.15 \mathrm{~mm} / \mathrm{rev}$. The cutting force is measured using a strain gauge dynamometer; an infrared pyrometer is utilized for measurement of surface temperature of workpiece and chip thickness is measured using an optical microscope.

\section{2D finite-element simulation of heat-assisted machining}

DEFORM 2D software, utilizing adaptive re-meshing technique and updated Lagrangian formulation, is applied in this study [19]. The workpiece is assigned as plastic; the mesh contains 30,000 elements with element size of $0.01 \mathrm{~mm}$ and the tool is considered as rigid. The thermomechanical properties of $\mathrm{Ti}-6 \mathrm{Al}-4 \mathrm{~V}$ and $\mathrm{WC}-\mathrm{Co}$ are incorporated in DEFORM software from its library as tabulated in table 1. A fine mesh is assigned in the cutting area of workpiece and tool tip of the insert. The workpiece cutting length $(3 \mathrm{~mm})$ is chosen so that it can complete a steady-state condition. The upper and right sides of the workpiece are allowed to transfer heat to the environment, whereas rake and clearance sides of the tool are allowed for heat transfer (figure 2). The heating tempearature for $\mathrm{Ti}-$ $6 \mathrm{Al}-4 \mathrm{~V}$ is selected based on the previous work [20].

Table 1. Thermo-mechanical properties of $\mathrm{Ti}-6 \mathrm{Al}-4 \mathrm{~V}$ and WC-Co.

\begin{tabular}{lcc}
\hline Properties & Ti-6Al-4V & WC-Co \\
\hline Density $\left(\mathrm{kg} / \mathrm{m}^{3}\right)$ & 4430 & $14.5 \times 10^{3}$ \\
Young's modulus $(\mathrm{GPa})$ & 113 & 640 \\
Thermal conductivity $\left(\mathrm{W} / \mathrm{m}^{\circ} \mathrm{C}\right)$ & 7 & 75.4 \\
Specific heat $\left(\mathrm{J} / \mathrm{kg}^{\circ} \mathrm{C}\right)$ & 546 & 220 \\
Poisson's ratio & 0.342 & 0.22 \\
\hline
\end{tabular}

Johnson-Cook material model, shear friction model $(m=0.7)$ and Cockroft and Latham fracture criterion are employed for chip segmentation of titanium alloy in the present study [21].

\section{Result and discussion}

\subsection{Effect of cutting speed, feed rate and heating temperature on cutting force}

The effect of cutting speed on cutting forces at preheating temperature of 200,400 and $30{ }^{\circ} \mathrm{C}$ is shown in figure 3 . The result shows a reduction by $18 \%$ of cutting force when machining Ti-6Al- $4 \mathrm{~V}$ from 30 to $400{ }^{\circ} \mathrm{C}$ at cutting speed of $40 \mathrm{~m} / \mathrm{min}$. Again there is a reduction of cutting force when cutting speed increases to $100 \mathrm{~m} / \mathrm{min}$. This is because higher cutting speed initially increases cutting temperature, reducing the strength of the material. The reduction of cutting force at higher cutting speeds is similar to that observed at $30{ }^{\circ} \mathrm{C}$.

In another case, by keeping cutting speed constant at $100 \mathrm{~m} / \mathrm{min}$ and changing feed rates, machining is performed. A $15 \%$ reduction in cutting force at $400{ }^{\circ} \mathrm{C}$ temperature is achieved as compared with the $30{ }^{\circ} \mathrm{C}$ case.

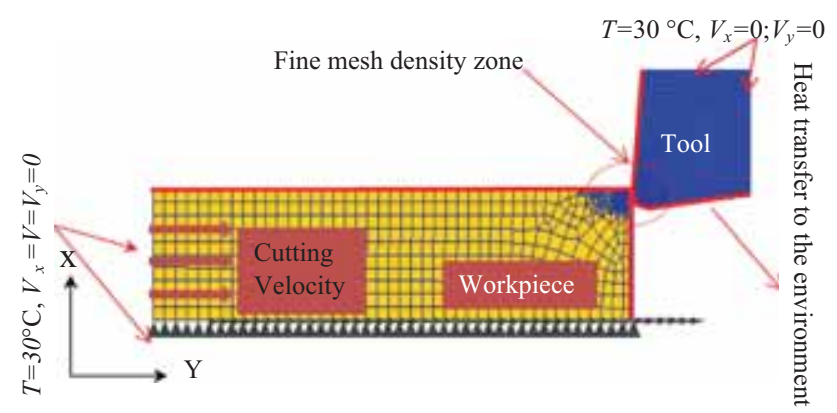

Figure 2. Tool and workpiece boundary condition. 


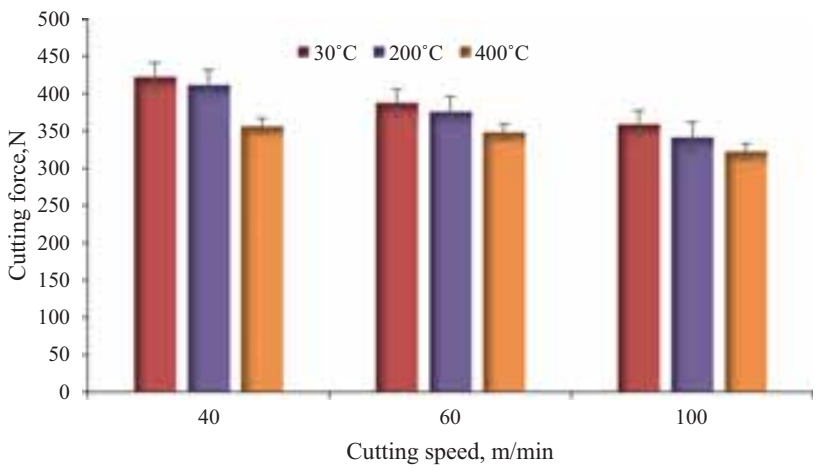

Figure 3. Measured cutting force at $f=0.13 \mathrm{~mm} / \mathrm{rev}$.

However, increase in feed rate from 0.1 to $0.15 \mathrm{~mm} / \mathrm{rev}$ increases the cutting force in both room and heating conditions, as shown in figure 4 . This may be because at higher feed rate, more vibration or chatter formation occurs, which increases the tool wear, resulting in increase of the force. A good agreement between simulation and experimental cutting force results is shown in figure 5 .

\subsection{Prediction of cutting zone temperature distribution}

Temperature distribution in the process zone is studied for both room and hot conditions. The temperature and heat produced in the cutting zone directly affect the temperature of the tool and machinability, which in turn also affects tool life, cutting force and tool wear. It is found that high cutting temperature is generated along with the chip temperature in hot turning operation $\left(830^{\circ} \mathrm{C}\right)$ as shown in figure 6 , which reduces the flow stress or effective stress of the material.

\subsection{Stress, strain and strain rate distribution}

The stress distribution in the cutting zone (primary and secondary deformation zone) is studied for room and preheating temperatures (figure 7). The use of heating on the workpiece surface increases the thermal softening of the

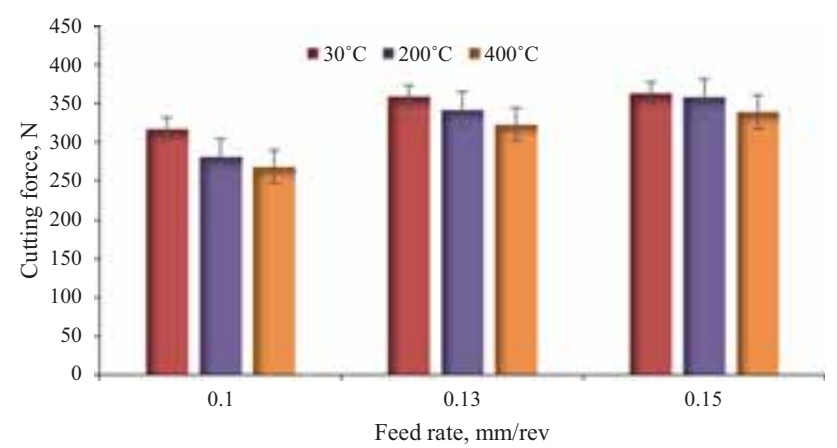

Figure 4. Measured cutting force at $V c=100 \mathrm{~m} / \mathrm{min}$.

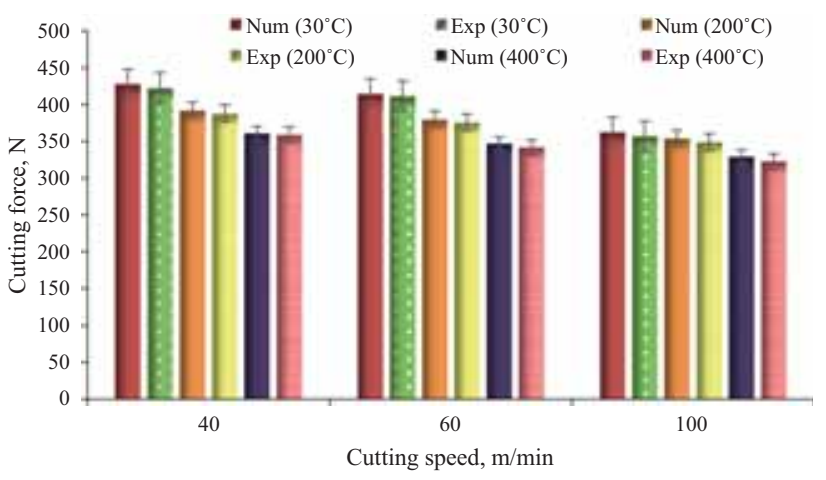

Figure 5. Simulation and experiment of cutting force at $f=0.13 \mathrm{~mm} / \mathrm{rev}$.

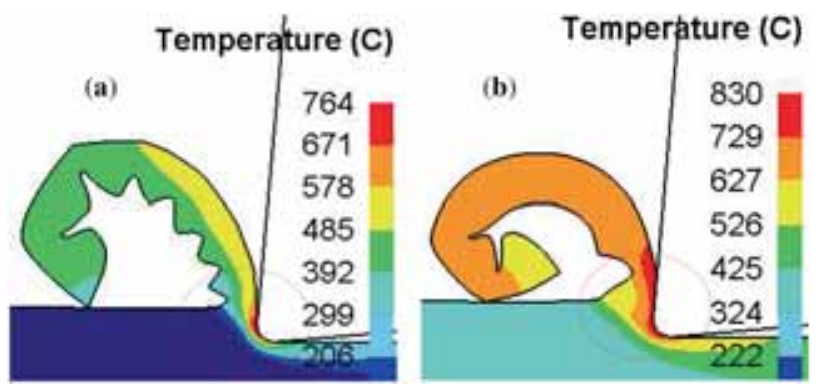

Figure 6. Temperature field in cutting region at $V c=40 \mathrm{~m} / \mathrm{min}$ and $f=0.1 \mathrm{~mm} / \mathrm{rev}$ : (a) $30{ }^{\circ} \mathrm{C}$ and (b) $400{ }^{\circ} \mathrm{C}$.
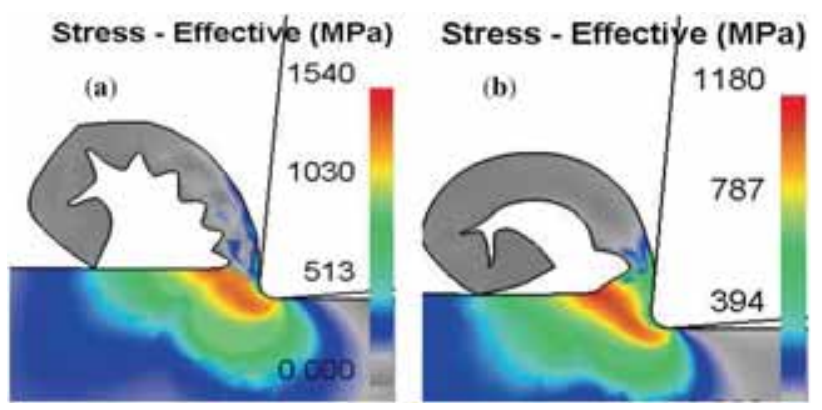

Figure 7. Effective stress on workpiece at $V c=40 \mathrm{~m} / \mathrm{min}$ and $f=$ $0.1 \mathrm{~mm} / \mathrm{rev}$ : (a) $30{ }^{\circ} \mathrm{C}$ and (b) $400{ }^{\circ} \mathrm{C}$.
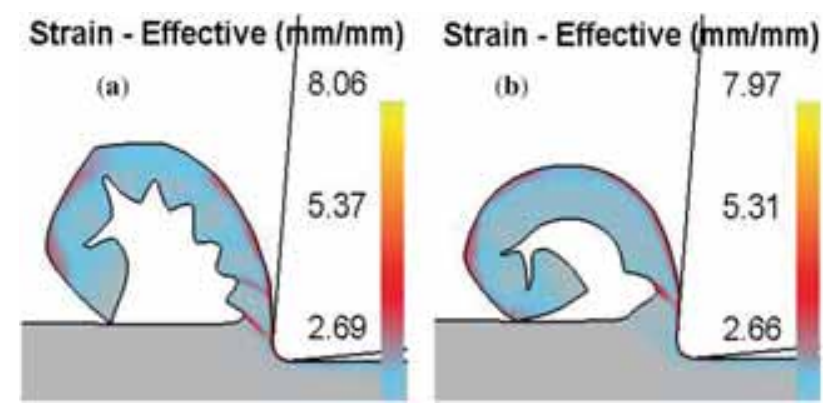

Figure 8. Effective strain on chip at $V c=40 \mathrm{~m} / \mathrm{min}$ and $f=0.1$ mm/rev: (a) $30{ }^{\circ} \mathrm{C}$ and (b) $400{ }^{\circ} \mathrm{C}$ 


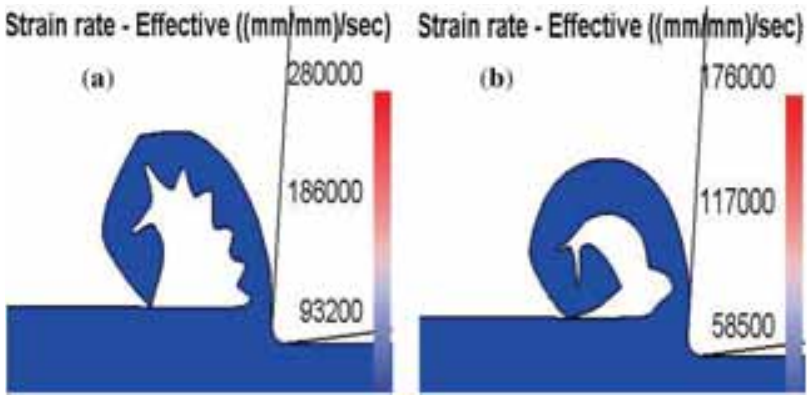

Figure 9. Effective strain rate in shear zone at $V c=40 \mathrm{~m} / \mathrm{min}$ and $f=0.1 \mathrm{~mm} / \mathrm{rev}$ : (a) $30{ }^{\circ} \mathrm{C}$ and (b) $400{ }^{\circ} \mathrm{C}$.

material. Hence less stress is induced in the process zone, and less energy consumption is required for maximum material removal. The maximum effective stress reaches $1540 \mathrm{MPa}$ at $30{ }^{\circ} \mathrm{C}$, whereas in preheating conditions the maximum stress drops to $1180 \mathrm{MPa}$. The material becomes softer at $400{ }^{\circ} \mathrm{C}$ due to rising temperature in the shear zone, along with flow stress getting reduced.
It is found that the strain is lower for preheating temperature at about 7.97 , whereas at $30{ }^{\circ} \mathrm{C}$ it is 8.06 (figure 8). The effective strain rate is higher at room temperature compared with the preheating temperature of $400{ }^{\circ} \mathrm{C}$. The strain rate value depends upon the width of the high strain rate zone and maximum nodal velocity. In preheating conditions, the nodal velocity decreases and the width of strain rate zone increases. This indicates that the application of heat is significant for the primary and secondary zones. The maximum strain rate obtained at room temperature is $176000((\mathrm{~mm} / \mathrm{mm}) / \mathrm{s})$ whereas the maximum strain rate at $400{ }^{\circ} \mathrm{C}$ is around $280000((\mathrm{~mm} / \mathrm{mm}) / \mathrm{s})$ as shown in figure 9. Higher strain rate in hot condition means lower stress in the cutting tool [17].

\subsection{Prediction of chip thickness and chip shape}

The simulations of chip formations are compared with the chips obtained from both room and hot turning. For better understanding of chip morphology, the chips are mounted

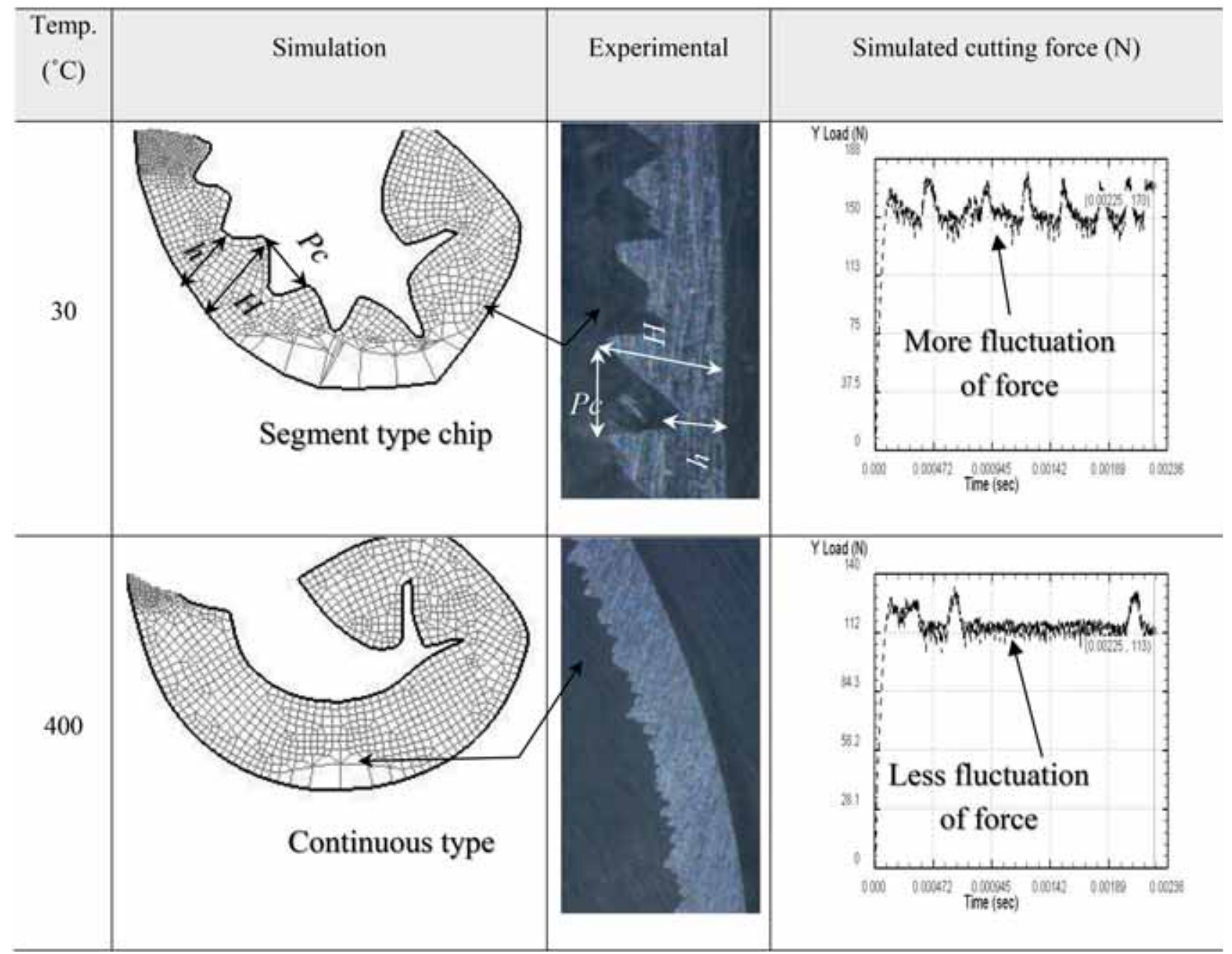

Figure 10. Chip morphology and cutting force at $V c=40 \mathrm{~m} / \mathrm{min}$ and $f=0.1 \mathrm{~mm} / \mathrm{rev}$ for room and hot conditions. 


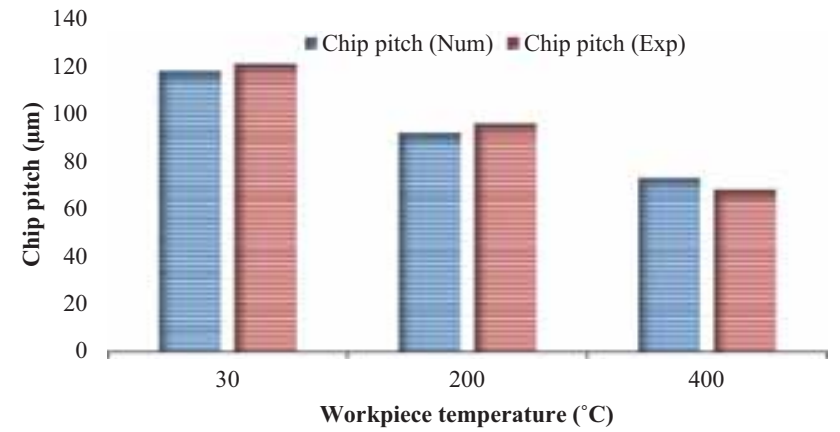

Figure 11. Comparison of simulation and experimental chip pitch with the heating temperature at cutting speed $40 \mathrm{~m} / \mathrm{min}$ and feed rate $0.1 \mathrm{~mm} / \mathrm{rev}$.

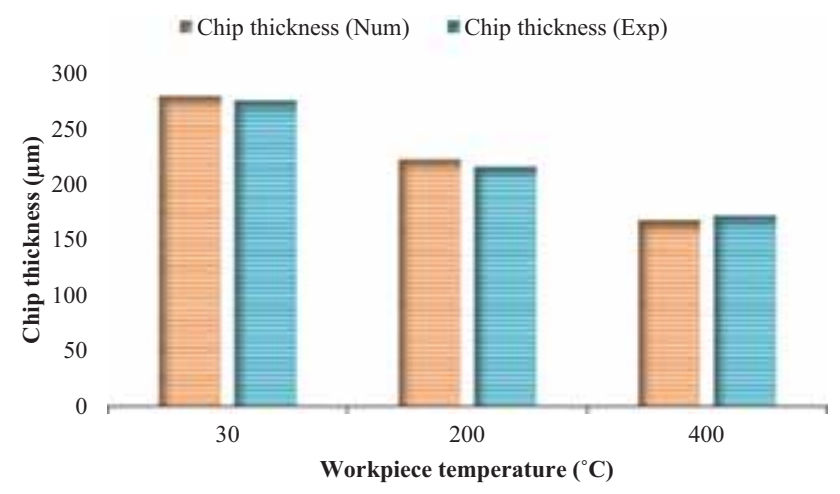

Figure 12. Comparison of simulation and experimental chip thickness at cutting speed $40 \mathrm{~m} / \mathrm{min}$ and feed rate $0.1 \mathrm{~mm} / \mathrm{rev}$.

and polished with different grades of sandpapers. At room temperature there is segmented type of chip whereas at hot condition, continuous chips are observed. The fluctuation in cutting force is the sign of segment type chip formation, whereas smooth force (less fluctuation) is observed in case of continuous chip formation at heating conditions (figure 10). The chip pitch $(P c)$ in case of room temperature machining condition is more. It is noticed that the chip thickness decreases with increased heating temperature. The reduction of chip thickness is the sign of reduction of cutting forces. The simulated and experimental chip pitch and thickness are shown in figures 11 and 12, respectively, and substantial agreement is noticed.

\section{Conclusions}

In this study, 2D finite-element model of hot machining of Ti-6Al-4V using tungsten carbide insert at different machining conditions is simulated. The simulation results are validated by carrying out an experimental plan with the same input parameters. From the analysis, the following conclusions are listed:
- Reduction of cutting force is observed in hot condition compared with room temperature due to an increase of process zone temperature. There is again a reduction of cutting force with the increase of cutting speed.

- The increase of feed rate increases the cutting force for both room and heating conditions.

- The increase of process zone temperature reduces the flow stress of the material. As a result, there is a reduction in shear strength.

- There is a reduction of chip thickness and chip pitch at heating condition as compared with room temperature.

- The effects of heating and absence of heating on predicted temperature, strain, stress and strain rate are also investigated. A good correlation between the experiment and simulation result is achieved.

\section{References}

[1] Upadhyay V, Jain P K and Mehta N K 2012 Machinability studies in hot machining of Ti-6Al-4V alloy. Adv. Mater. Res. 622-623: 361-365, https://doi.org/10.4028/www.scien tific.net/amr.622-623.361

[2] Rahman Rashid R A, Bermingham M J, Sun S, Wang G and Dargusch M S 2013 The response of the high strength Ti10V-2Fe-3Al beta titanium alloy to laser assisted cutting. Precis. Eng. 37: 461-472, https://doi.org/10.1016/j.pre cisioneng.2012.12.002.

[3] Sun S, Brandt M, Barnes J E and Dargusch M S 2011 Experimental investigation of cutting forces and tool wear during laser-assisted milling of Ti-6Al-4V alloy. Proc. Inst. Mech. Eng. Part B: J. Eng. Manuf. 225: 1512-1527, https:// doi.org/10.1177/0954405411411608

[4] Ginta T L and Amin A K M N 2013 Thermally-assisted end milling of titanium alloy Ti-6Al-4V using induction heating. Int. J. Mach. Mach. Mater.14: 194-212, https://doi.org/10. 1504/ijmmm.2013.055737

[5] Fnides B, Yallese M A, Mabrouki T and Rigal J F 2011 Application of response surface methodology for determining cutting force model in turning hardened AISI H11 hot work tool steel. Sadhana - Acad. Proc. Eng. Sci. 36: 109-123, https://doi.org/10.1007/s12046-011-0007-7

[6] Akasawa T, Takeshita H and Uehara K 1987 Hot machining with cooled cutting tools. CIRP Ann. - Manuf. Technol. 36: 37-40, https://doi.org/10.1016/s0007-8506(07)62548-7

[7] Leshock C E, Kim J N and Shin Y C 2001 Plasma enhanced machining of Inconel 718: modeling of workpiece temperature with plasma heating and experimental results. Int. J. Mach. Tools Manuf. 41: 877-897, https://doi.org/10.1016/ s0890-6955(00)00106-1

[8] Tosun N and Ozler L 2004 Optimisation for hot turning operations with multiple performance characteristics. Int. J. Adv. Manuf. Technol. 23: 777-782, https://doi.org/10. 1007/s00170-003-1672-4

[9] Maity K P and Swain P K 2008 An experimental investigation of hot-machining to predict tool life. J. Mater. Process. Technol. 198: 344-349, https://doi.org/10.1016/j. jmatprotec.2007.07.018 
[10] Baili M, Wagner V, Dessein G, Sallaberry J and Lallement D 2011 An experimental investigation of hot machining with induction to improve Ti-5553 machinability. Appl. Mech. Mater. 62: 67-76, https://doi.org/10.4028/www.scientific. net/amm.62.67

[11] Liu X, Xu W J, Sun J and Zhang L 2012 Research on heating resistance in electric hot machining. Adv. Mater. Res. 430-432: 209-212, https://doi.org/10.4028/www.scientific. net/amr.430-432.209

[12] Muhammad R, Ahmed N, Shariff Y M and Silberschmidt V V 2012 Finite element analysis of forces in drilling of Tialloys at elevated temperature. Solid State Phenom. 188: 250-255, https://doi.org/10.4028/www.scientific.net/ssp.188. 250

[13] Muhammad R, Maurotto A, Roy A and Silberschmidt V V 2012 Hot ultrasonically assisted turning of $\beta-\mathrm{Ti}$ alloy. Procedia CIRP 1: 336-341, https://doi.org/10.1016/j.procir. 2012.04.060

[14] Xiang H, Fu J and Chen Z 2006 3D Finite element modeling of laser machining PMMA. In: Proceedings of the IEEE Conference, vol. 1, pp. 942-946

[15] Singh G, Teli M, Samanta A and Singh R 2013 Finite element modeling of laser-assisted machining of AISI D2 tool steel. Mater. Manuf. Process. 28: 443-448, https://doi.org/ 10.1080/10426914.2012.700160

[16] Zamani H, Hermani J P, Sonderegger B and Sommitsch C 2013 3D simulation and process optimization of laser assisted milling of Ti6Al4V. Procedia CIRP 8: 75-80, https://doi. org/10.1016/j.procir.2013.06.068.

[17] Shi B, Attia H, Vargas R and Tavakoli S 2008 Numerical and experimental investigation of laser-assisted machining of Inconel 718. Mach. Sci. Technol. 12: 498-513, https://doi. org/10.1080/10910340802523314

[18] Parida A K and Maity K 2018 Analysis of some critical aspects in hot machining of Ti-5553 superalloy: experimental and FE analysis. Def. Technol., https://doi.org/10.1016/j.dt.2018.10.005

[19] DEFORM 3D Version 11.02016 User manual. SFTC, Columbus, Ohio State

[20] Joshi S, Tewari A and Joshi S 2014 Influence of preheating on chip segmentation and microstructure in orthogonal machining of Ti6Al4V. J. Manuf. Sci. Eng. 135: 1-11, https://doi.org/10.1115/1.4025741

[21] Umbrello D 2008 Finite element simulation of conventional and high speed machining of Ti6Al4V alloy. J. Mater. Process. Technol. 196: 79-87, https://doi.org/10.1016/j.jmat protec.2007.05.007 